\title{
Research-based learning: Designing the course behind the research
}

\author{
Elizabeth A. Beckmann, Xénia Weber, Michael Whitehead, \\ Adrienne Nicotra
}

It is hoped that the papers in this book have encouraged readers to share the authors' appreciation of the ecology of Kosciuszko National Parkits diversity, variability, subtlety and uniqueness. The authors also hope readers have been intrigued, challenged and informed by the research problems tackled in the papers, as well as the scientific responses and solutions to those problems. This chapter explains a little more of the way in which this research came about, and makes some connections across some key findings. It also explains the pride that the course design team (the authors of this chapter) have in the work of the papers' authors, most of whom had just a couple of semesters of university study when they embarked on this research.

\section{A vision for research-based learning}

In mid-2015, Adrienne Nicotra, Elizabeth (Beth) Beckmann, Xénia Weber and Michael Whitehead came together to plan how to realise Adrienne's vision of bringing together a group of Australian National University (ANU) science students, who had just finished their first year of study, to help them share their enthusiasm, knowledge, skills and energy in a research-based field ecology course. This teaching design team was diverse: Adrienne, a plant science researcher and renowned educator with extensive knowledge in her field and beyond; Beth, a biologist and environmental communication specialist turned educational designer and researcher; Michael, a recent $\mathrm{PhD}$ graduate in evolutionary ecology with a passion for teaching; and Xénia, an Honours year science undergraduate experienced in running peer-assisted learning sessions for first-year students. As the team shared ideas and experiences in the context of Adrienne's vision, the structural and pedagogical elements of the course became clear. The plan was for a two-week residential course in Australia's Snowy Mountains, specifically within the high-elevation country of 
Kosciuszko National Park. ${ }^{1}$ This was finalised into a fortnight in early December (after the end of the academic year, and at the beginning of summer) at Charlotte Pass, just four hours from the university campus. The logistics of travel, residential living and cost in this mildly isolated spot would be complex but manageable.

In terms of its approach to learning, the course was designed to be constructivist (Honebein 1996) in its intention of creating an intellectually challenging research-based educational environment (Healey 2005). It was integral to the pedagogical design that the students would be the primary researchers: identifying research problems inspired by the ecological contexts around them, designing experimental approaches, collecting data, analysing that data in the context of the research problem and presenting their findings, both orally and in writing, to their peers. The proposed course was innovative and definitely ambitious. In an approach that constitutes the research-based education equivalent of rapid prototyping, small teams of students would work through four different research projects over 12 days, iteratively practising and developing their experimental and critical-thinking skills again and again in different contexts.

Crucially, the field expertise of experienced researchers was an important resource to be shared with the students. These 'resource people' were instructed to support and gently guide the students, rather than provide prescriptive leadership based on their expertise. This model drew on Beth's understanding of authentic learning in field courses (Beavis and Beckmann 2012), and especially on Adrienne's experience of a field course run by the Organisation for Tropical Studies during her own doctoral studies.

1 Kosciuszko National Park (KNP) was named by the Polish explorer and 'discoverer' Strzelecki in honour of his national hero General Kosciuszko. At 2,030 m, it is the highest mountain in Australia. Within KNP, at $1,760 \mathrm{~m}$ above sea level, Charlotte Pass is the highest permanent settlement in Australia and provides relatively easy access to Mt Kosciuszko. It is crucial to remember, however, that KNP and all the high-elevation environments were well known to the local Indigenous people for thousands, if not tens of thousands, of years before such 'discoveries'. The authors are heartened that in 2016 the NSW Government signed a Memorandum of Understanding with the Monaro Ngarigo people, solidifying the local Indigenous community's role in preserving KNP's cultural as well as natural heritage. The authors acknowledge the local Indigenous people, and especially pay respect to their elders past, present and emerging. 
Although the team initially had some concern as to whether ANU staff researchers would be convinced by the model and able to 'let go' when working with early year undergraduates rather than doctoral researchers, these concerns proved unfounded. A few days in the alpine environment turned out to be a great drawcard for ecology-minded colleagues at ANU, with senior $\mathrm{PhD}$ students and postdocs joining research fellows in volunteering their expertise and enthusiasm. All appeared to find it very natural to focus on the undergraduates driving each project, as they identified their own developing passions and motivations in ecology.

As the design team realised that the course was developing along quite innovative lines, the decision was made to seek university human research ethics approval (ANU Protocol 2015/553) to allow the course to be framed within its own scholarly pedagogical research context and the outcomes more formally assessed and disseminated. (This is planned for future journal papers, as well as through this overview.) The team focused especially on developing thoughtful student feedback surveys, which included creating comparable data sources by adapting questions from published research (Durrant and Hartman 2014; Howitt et al. 2014). A mid-course whole group discussion, facilitated by Beth as the non-residential 'outsider', gave students an option to provide formative feedback during the two-week stay, which led to useful changes for the second half of the course, as well as complementing the other sources of feedback to guide the design of future iterations of the course.

\section{Crafting the workshops}

With some key structural elements in place, the next step was to ensure that creativity of the approach was grounded in evidence-based pedagogical strategies. Given the time constraints of an intensive course, students would need to hit the ground running. Some pre-residential readings were considered essential to ensure a reasonable common background in relevant ecological and methodological topics. Beyond theoretical academic knowledge, the team wanted the students to consolidate other crucial scientific skills, such as teamwork, collaboration and communication. To do this, 'just in time' workshops were planned for delivery during the field trip. Xénia’s background in peer-assisted learning came to the fore here, and she and Michael began to develop some of the innovative workshops that would take place on-site. Modelling 
what was intended to happen in the field, Adrienne and Beth became the educational 'resource people' and mentors for Xénia and Michael, encouraging a shared reflective practice and stepping into the background as these two identified and addressed their own research areas. Xénia's reflective journal shares her thinking at the time:

Group work and reflective practice were two important skills I was particularly keen on fostering among the students. I was also convinced of the importance in tackling these skills explicitly rather than implicitly, because I wanted us to take a different-better-approach than how I'd been taught. My experiences in terms of 'reflection' at school had been largely negative: there was no real explanation of the value of reflection or what good reflective writing actually looked like. Similarly, my experiences associated with group work had been poor. Either staff encouraged (or mandated) group activities and hoped that positive student outcomes would emerge from the opportunity, or teachers would simply recite key qualities associated with good group work (such as letting everyone participate, or respecting differences of opinion in a constructive way). There was never any in-depth exploration of how or why particular behaviours emerge in teams, or what strategies could be used to deal with these behaviours.

As we discussed options for the ecology course, I realised we could offer unique workshops in reflection and group work that would offer students new material, grounded in current research. This latter point became a real focus, especially after a chance discussion with Andrew Frain ${ }^{2}$ in the ANU Research School of Psychology, who described how he was using social identity concepts to workshop collaboration and leadership skills. We were working with two overlapping identity groups - university students' and 'ecological researchers'-so it made sense to present them with the current developments and insights of psychological researchers into group dynamics, individual perceptions of identity and motivation, including the elements of complexity and uncertainty.

As thoughtful educators, Xénia and Michael took on the task of steeping themselves in the relevant knowledge before designing the workshops. First, they developed a literature review and research database, and learned about others' experiences with implementing such projects in tertiary education. From this background, they distilled the kinds of workshop that they wanted to create, and we all brainstormed how we could connect

2 Dr Andrew Frain is now Senior Evaluation Analyst, Planning and Performance Measurement and Teaching Fellow in the Strategic Defence Studies Centre at The Australian National University. 
these to other elements of the course (e.g. through a reflective journal and post-workshop surveys) to enhance learning outcomes and evaluate the teaching. Again, Xénia's reflections provide a powerful insight into this planning phase.

In preparing to teach about collaboration, Michael and I met regularly with Andrew [Frain] in a form of tuition/book club where we would discuss Haslam's social identity approach (2004) and Andrew's own blog. ${ }^{3}$ These opportunities were invaluable for posing questions, challenging and eventually understanding the theories on social identity, group/individual motivations and how these could be best presented to students to develop their collaborative skills. This dramatically altered our initial plans of focusing on topics such as 'working in teams', 'active listening', 'conflict resolution' and 'appreciating and benefiting from diversity'. Instead, we sought to understand ways in which we could convey to students how individual/group identities form, how this affects attitudes/behaviour, the implications for functional/dysfunctional groups and opportunities for improving group motivation and collaboration by understanding the underlying processes.

Similarly, although I had used reflective writing many times throughout my academic studies and teaching roles, I sought a stronger basis for how best to instruct and make the process of reflection more accessible and transparent to those who might be less familiar with, or confused about, the genre. I read numerous papers and resources, mostly recommended by Beth, and found the work by Moon (1999) and by the ANU team of Howitt et al. (2014) particularly helpful in providing practical strategies to teach high-quality reflective practice.

As we began to develop the workshop materials, we realised that repeated exposure and interaction with the theories of reflection and collaboration would be critical for our students to understand and 'own' all these concepts. We therefore created a one-page handout to highlight to prospective students how our approach to collaboration would be different, the basis of the social identity approach and why we thought it would be so influential in the course. We also explained these concepts when we introduced the students to their field notebook assessment task, outlining our expectations and the emphasis on reflective quality (rather than quantity), with guiding questions to help reflection.

3 Tame, R, Frain, A (2015) Social identity resources. socialidentityresources.com/. 
The final outcome of this development approach was a set of three workshops ${ }^{4}$ that introduced and then built on concepts of self-categorisation (as individuals and then as groups), social identity, effective collaboration (and how this could be supported or antagonised) and reflective writing (as a practical skill for recording a researcher's activities and as a tool to enhance critical thinking). There was much thought put into presenting these concepts, appropriately contextualised to provoke humour and engagement. For example, recognising the strength of imagery in effective communication but unimpressed with the typical business focus of social identity concepts in published research, Xénia and Michael instead came up with the traits of the 'busy bird' and the 'lazy sloth' as a discussion point around group dynamics. Despite the apparent simplicity of this analogy, which initially concerned some students, these terms rapidly became a shorthand readily used by students in their written reflections. Indeed, some were even overheard referring to themselves or their team members going into 'sloth' or 'bird' mode during the course of the day's work. This approach helped students gain a much more personalised understanding, evidenced in their individual reflective journals, of the waxing and waning of an individual's roles and contributions in a team that must work intensely and consistently together on a single project over several days.

\section{The research outcomes}

By all indicators, the course was a great success. The students rose beautifully to the task of leading, designing and communicating their research, and improved their skills and elegance across all these aspects as they moved through the four projects. The availability of highquality digital cameras (mostly in their mobile phones) was put to great use to record data. The quality of their research outcomes can be seen throughout this book. While the work of not yet polished researchers, and naturally limited in scope, the formal peer-review process ensured that all these papers report reliable findings that may have otherwise remained unknown, and that have the potential to guide future researchers towards interesting problems.

4 See Workshops 3, 4 and 7 in the 'Workshop summaries' section. 
Science holds 'firsts' in high regard. This volume reports the first study on circadian rhythms in the iconic snow gum (Eucalyptus pauciflora), where Mauger et al. show convincing evidence for diurnal rhythms in photosynthesis as measured by stomatal activity. In another first for an iconic alpine species, Zucher et al. test the hypothesis that tiling aggregation in bogong moths is a behavioural adaptation to mitigate water loss. While the experimental results run opposite to this compelling hypothesis, this only deepens the mystery surrounding this curious behaviour.

In a changing climate, Australia's alpine ecosystems are likely to be some of the most vulnerable. This concern is addressed by student teams in several of the studies reported in this volume. McLeod et al. contributed evidence of local acclimation of photosynthesis in snow gums. In their studies on alpine skinks, and perhaps controversially, both Hammer et al. and Robinson et al. suggest that 'some like it hot', and that these reptiles might actually benefit under projected temperature increases. Local data and results like these are crucial for refining climate change models.

\section{The course's reception by students}

The three workshops on identity, collaboration and reflective practice were particularly successful in providing the students with practical skills and new perspectives on thinking about themselves and their own collaborative interactions in terms of human social behaviour. Again, it is instructive to draw on the reflections of Xénia as the educational researcher that she had become:

Short presentations were crucial after a long day in the field. An hour was ample to cover all material, and the evening timeslots made the small group interactions and discussion more relaxed and helpful in terms of planning the next day. While behavioural and conceptual 'worldview' learning outcomes are particularly challenging to measure, I was happy with the material we delivered and felt it was a unique and important contribution to the students' learning. To be truthful, I had expected some critique and apprehension about these 'different' ideas, but instead the post-workshop anonymous feedback was exceptionally encouraging. With just the few hours of the workshops, and the encouragement to continue reflecting, many insights seemed to be emerging among the students in regard to their working relationships and their observations in the field. It became clear that the concepts being presented were actually influencing students' ideas and behaviour. Even over the first week, I saw evidence in the students of increasing self-awareness, analytical skills 
and an expanded repertoire of potential explanations to social dynamics. I myself am pleased to have learnt and thought about these concepts, and can see the value in pursuing them more myself, especially integrated into other teaching roles.

Thinking and writing reflectively on nature is a well-known characteristic of ecologists_influential writers such as Aldo Leopold, Tracey Storer, Konrad Lorenz and Rachel Carson spring to mind-so it was in keeping with the research-led focus to build on the reflective practice aspects in the assessment schedule. As well as individual field notebooks that required daily entries of notes and data, students were asked to write at least three reflective contributions in their journals each week. With many students writing even more frequently than requested, these reflective journals provided an amazing wealth of written and visual commentary on the individual learning pathways, research discoveries and lessons from residential and collaborative relationships and experiences that the course had facilitated. That the students had especially learned to value reflective practice as learners and scientists was evident in the anonymous postcourse feedback, as the below examples show:

I think reflection and also keeping a field diary is incredibly helpful because you can look back and see what you've learnt or what needs fixing, or how certain data can be helpful even if it's not for what you first thought you were studying or had envisaged your results to say.

... I still have a lot to learn when it comes to reflective practice. However, over the course of just 2 weeks I have gone from being a complete skeptic to appreciating the value of reflection, both personally and scientifically.

The focused workshops and field journal practices on reflection did help in the research and investigation and analysis processes. Having an immediate way to apply that reflection - to the field problems and our field books - gave relevance to our study of reflective practice and helped us to see the significance of it, and solidified the skills, more so than if they were simply mentioned [in] a lecture and never followed up with application.

It was good to have a sense of how I was coping with the course through writing down my experiences... 
Collecting such a range of student feedback-formal from post-course surveys and informal from on-site conversations, the mid-course focus group and students' own reflective journals - was very valuable and confirmed the design team's sense of success. Interestingly, the main issue from the mid-course group discussion was the way the evening cooking/cleanup groups were structured, rather than anything to do with the research aspects, reminding everyone of the importance of having a holistic view when designing and implementing residential courses.

In the post-course surveys, all students strongly agreed that the course had allowed more direct interaction with lecturers and researchers than had occurred in their previous year of university study. They also reported that they had learned more than in lectures or laboratory practicals, that they had been able to apply their learning immediately and that they had enjoyed meeting new people and working with others. The challenges were, of course, evident, but for the most part students acknowledged these positively:

Collaborative projects are challenging in themselves, but it was definitely the immense pressure to perform in a small amount of time that was the most difficult. I think this was helped by the great support and assistance of the resource people, and the general enthusiasm/dedication of all of the students on the course.

The responses to open-ended questions-which repeatedly showed that the learning goals of the course had become the learning outcomes of its students - often provided unexpected joy in the hearts of the design team as educators and scientists:

The field course definitely has changed my perception on research ... [It's] not just about discovering new things, although it is an exciting part. It is also about confirming already established ideas, or disproving them and creating new theories.

From the lectures to the practical fieldwork, this course has been an experience I will never forget. I do not regret anything about it and look forward to applying all the skills I have picked up.

In summary, the 2015 inauguration of the Field Studies in Functional Ecology course at The Australian National University was a great success. It also provided the members of the design team-self-identified as lifelong learners-many opportunities to tweak and improve specific elements. 
This has been done in the subsequent successful iterations of the courseagain at Charlotte Pass in 2016 and, taking the concept to tropical north Queensland, in the Daintree rainforest in 2017. Interestingly, several of the 2015 students chose to have a second bite of the cherry, which required another level of thought around appropriate learning outcomes for those doing the course for the second time. Future volumes in this series will document the research findings of those later scientific adventures.

It is fitting, however, for the final words of this volume to come from a 2015 student, whose reflective feedback epitomises the research-focused outcome that the design team initially envisaged, and that made the many, many exhausting days and weeks spent on planning, executing and evaluating this course so worthwhile:

I believe that I now am more capable at looking at the world scientifically and seeing questions where I used to just see curiosities.

\section{References}

Beavis, S, Beckmann, EA (2012) Designing, implementing and evaluating a consultancy approach to teaching environmental management to undergraduates. International Research in Geographical and Environmental Education 21(1): 71-92. doi.org/10.1080/10382046. 2012.639151

Durrant K, Hartman TPV (2014) The integrative learning value of field courses. Journal of Biological Education 49(4): 385-400. doi.org/10.10 80/00219266.2014.967276

Haslam, SA (2004) Psychology in Organisations: The Social Identity Approach, 2nd edn. Sage, London.

Healey, M (2005) Linking research and teaching: Exploring disciplinary spaces and the role of inquiry-based learning. In Barnett, R (ed.), Reshaping the University: New relationships between research, scholarship and teaching, pp. 67-78. Society for Research into Higher Education and Open University Press, Maidenhead.

Honebein, P (1996) Seven goals for the design of constructivist learning environments. In Wilson, BW (ed.), Constructivist Learning Environments: Case studies in instructional design, pp. 17-24. Educational Technology Publications, New Jersey. 
Howitt, S, Wilson, A, Higgins, D (2014) Teaching research: Evaluation and assessment strategies for undergraduate research experiences (TREASURE), Final Report 2014. Australian Government Office for Learning and Teaching, Sydney.

Moon, J (1999) Reflection in Learning and Professional Development: Theory and practice. Routledge-Falmer, Abingdon. 
This text is taken from Researching functional ecology in Kosciuszko

National Park, edited by Hannah Zurcher, Chia Ming-Dao, Michael Whitehead and Adrienne Nicotra, published 2017 by ANU eView, The Australian National University, Canberra, Australia. dx.doi.org/10.22459/RFEKNP.11.2017.14 